OPEN ACCESS

Edited by:

Anne L. Astier,

INSERM UMR1291 CNRS UMR5051

Université Toulouse III, France

Reviewed by:

Gill Diamond,

University of Louisville, United States

Christine Noel Metz,

Feinstein Institute for Medical

Research, United States

${ }^{*}$ Correspondence:

Qutayba Hamid qutayba.hamid@mcgill.ca

Specialty section:

This article was submitted to Inflammation,

a section of the journal

Frontiers in Immunology

Received: 27 May 2021 Accepted: 10 August 2021 Published: 26 August 2021

Citation:

Plesa M, Gaudet M, Mogas A, Jalaleddine N, Halayko A,

Al Heialy S and Hamid Q (2021) Vitamin D3 Attenuates Viral-Induced Inflammation and Fibrotic Responses in Bronchial Smooth Muscle Cells.

Front. Immunol. 12:715848. doi: 10.3389/fimmu.2021.715848

\section{Vitamin D3 Attenuates Viral-Induced Inflammation and Fibrotic Responses in Bronchial Smooth Muscle Cells}

\author{
Maria Plesa ${ }^{1}$, Mellissa Gaudet ${ }^{1}$, Andrea Mogas ${ }^{1}$, Nour Jalaleddine ${ }^{2}$, Andrew Halayko ${ }^{3}$, \\ Saba Al Heialy ${ }^{1,2}$ and Qutayba Hamid ${ }^{1,4,5^{*}}$ \\ 1 Translational Research in Respiratory Diseases, Meakins-Christie Laboratories, Research Institute of the McGill University \\ Health Center, Montréal, QC, Canada, ${ }^{2}$ Mohammed Bin Rashid University of Medicine and Health Sciences, College of \\ Medicine, Dubai, United Arab Emirates, ${ }^{3}$ Departments of Physiology and Pathophysiology, Children's Hospital Research \\ Institute of Manitoba, Winnipeg, MB, Canada, ${ }^{4}$ Faculty of Medicine, McGill University, Montréal, QC, Canada, ${ }^{5}$ College of \\ Medicine, University of Sharjah, Sharjah, United Arab Emirates
}

Toll-like receptor 3 (TLR3) activation by viral infections plays a key role in promoting inflammatory immune responses that contribute to pulmonary fibrosis in chronic inflammatory respiratory diseases. Vitamin D3 has been shown to be beneficial to patients with asthma and chronic obstructive pulmonary disease (COPD) through its anti-inflammatory and anti-fibrotic properties. Smooth muscle cells are one of the major contributors to airway remodeling in asthma and COPD. We therefore aimed to investigate the effect of vitamin D3 treatment on viral-induced TLR3 responses in Bronchial Smooth Muscle Cells (BSMCs) as a mechanism contributing to pulmonary fibrosis in asthma and COPD. Primary BSMCs from patients with asthma $(n=4), \operatorname{COPD}(n=4)$, and healthy control subjects $(n=6)$ were treated with polyinosinic: polycytidylic acid (polyl:C), TLR3 agonist in the presence or absence of vitamin D3 $(1,25 D 3)$. Here we report the mRNA expression and protein levels of pro-inflammatory and pro-fibrotic markers (IL-6, IFN- $\beta 1$, CCL2/MCP-1, fibronectin 1 and type I collagen) among BSMCs groups: asthma, COPD, and healthy controls. We show that at the baseline, prior to polyl:C stimulation, asthma and COPD BSMCs presented increased pro-inflammatory and pro-fibrotic state compared to healthy control subjects, as measured by quantitative PCR and immunoassays (ELISA/Flow Cytometry. Ligation of TLR3 by polyl:C in BSMCs was associated with increased TLR3 mRNA expression, and 1,25D3 treatment significantly reduced its expression. In addition, $1,25 \mathrm{D} 3$ decreased the expression of IL-6, IFN- $\beta 1, C C L 2$, FN1 and COL1A1 induced by polyl:C in BSMCs. The regulatory effect of 1,25D3 treatment on polyl:C-stimulated BSMCs was further confirmed at protein levels. Our findings suggest that vitamin D3 attenuates TLR3 agonist-induced inflammatory and fibrotic responses in BSMCs and support the clinical relevance of vitamin D3 supplementation in patients with viral infections having chronic respiratory diseases, such as asthma and COPD.

Keywords: asthma, COPD, vitamin D3, polyl:C, pulmonary fibrosis 


\section{INTRODUCTION}

Pulmonary fibrosis is a complex process that involves activation of several pattern recognition receptors (PRRs) and an interplay of many cell types that contribute directly or indirectly to airway remodeling. Increased thickness of the airway smooth muscle (ASM) layer due to hypertrophy and hyperplasia of ASM cells is a feature of airway remodeling in both asthma and chronic obstructive pulmonary disease (COPD) $(1,2)$. Bronchial smooth muscle cells (BSMCs) have been described as an important source of many pro-inflammatory and pro-fibrotic mediators (3). Therefore, increased proliferation of smooth muscle and excessive secretion may contribute to increased airflow obstruction and extracellular matrix (ECM) deposition, ultimately leading to fibrosis in patients with asthma and $\operatorname{COPD}(4,5)$.

Patients with chronic respiratory diseases are more susceptible to viral infections and contribute to disease exacerbation and progression due to an exaggerated immune response (6). Most viral responses are regulated by innate immune mechanisms through the activation of Toll-like receptors (TLRs) (7). Although several TLRs are activated in antiviral infections, TLR3 activation is triggered by double-stranded (ds) RNA motifs, a viral replication intermediate that is produced by positive-single-stranded RNA viruses $(8,9)$. TLR3 is located intracellularly, attached to the membrane of endosomes, and expressed in many cell types, including airway smooth muscle cells (10). After binding the dsRNA motif, TLR3 dimerizes and recruits the TIR-domaincontaining adapter-inducing interferon- $\beta$ (TRIF) protein (11) to the endosome, which results in activation of pro-inflammatory transcription factors, namely interferon regulatory factors (IRFs), and nuclear factor кappa B (NF-KB) $(9,12)$. TLR3 signaling via TRIF results in the upregulation of multiple pro-inflammatory cytokines, such as interleukin-6 (IL-6), IL-1 $\beta$, tumor necrosis factor-alpha (TNF- $\alpha$ ) and chemokines. The chemokine (CXC motif) ligand 10 (CXCL10) and the chemokine (CC motif) ligand 2 (CCL2), encoding monocyte chemoattractant protein 1 (MCP-1), are potent inflammatory mediators involved in inflammatory immune cell migration. These pro-inflammatory mediators have been recently described in the context of viral infections (13) and activates $\mathrm{T}$ helper 1 (Th1) cell-mediated immune responses. Increases in pro-inflammatory mediators in viral infections, in turn, may further activate signaling pathways involved in fibrosis (14), characterized by excessive deposition of ECM proteins, mostly fibronectin 1 (FN1) and type I collagen (COL1A1) (15).

Several clinical studies have associated vitamin D deficiency with increased risk of pathogenesis in patients with chronic lung diseases, such asthma and COPD (16-18). Moreover, vitamin D3 $(1,25 \mathrm{D} 3)$ has been shown to modulate innate immune responses in various cell types, including BSMCs (19), through its binding to vitamin $\mathrm{D}$ receptors (VDRs) that downregulate several proinflammatory transcription factors activated during infections $(20,21)$. In addition, vitamin D3 influences the expression and activity of various TLRs (20), essential in the immune response against viral infections (22).

Although TLR3 has a major role in viral-induced immune responses, excessive TLR3 inflammatory responses may play a key role in promoting exacerbations and fibrosis in asthma and
COPD. Therefore, in this study, we investigated the implications of vitamin D3 in offsetting pro-inflammatory and pro-fibrotic responses induced by TLR3 agonist, polyI:C in BSMCs isolated from asthmatic, COPD, and healthy control (non-smokers and smokers) subjects. We hypothesized that 1,25D3 treatment downregulates polyI:C-induced pro-inflammatory and profibrotic responses in BSMCs. We assessed the mRNA expression of TLR3, CYP24A1 and $V D R$, as a possible mechanism involved in these responses. Subsequently, we determined the mRNA expression and protein levels of selected markers (IL-6, IFN- $\beta 1$, CCL2, fibronectin 1 and type I collagen) before and after exposing the BSMCs to polyI:C, either alone or combined with $1,25 \mathrm{D} 3$ treatment. Our results suggest that vitamin D3 may play a protective role in the development of exacerbations due to viral infections, by its ability to regulate TLR3 responses in BSMCs.

\section{MATERIALS AND METHODS}

\section{Human Sample Characteristics}

For asthma experiments, Bronchial Smooth Muscle Cells (BSMCs) from non-asthmatic $(n=3)$ and asthmatic $(n=4)$ subjects were purchased from a commercial source (Lonza, MD, United States). These cells were chosen from subjects who were age-matched and non-smokers. For COPD experiments, BSMCs were obtained from the Hospital Research Institute of the University of Manitoba, as previously described (23). All procedures were approved by the Human Research Ethics Board of the University of Manitoba. These cells were chosen from subjects who were age-matched, smokers non-COPD $(n=3)$ and smokers COPD $(n=4)$. Table 1 describes the characteristics of the subjects included in this study.

\section{BSMCs Culture and Treatment}

BSMCs from passages two to five were maintained in Dulbecco's Modified Eagle's Medium (DMEM) (Gibco-BRL Inc. Carlsbad, USA) supplemented with 10\% Fetal Bovine Serum (FBS) and 1\% Penicillin-Streptomycin in a humidified $5 \% \quad \mathrm{CO}_{2} / 37^{\circ} \mathrm{C}$ incubator. For experiments, the cells were seeded into 12 - or 6 well plates at a cellular density of $1 \times 10^{5}$ cells and $2 \times 10^{5}$ cells, respectively. At $\sim 80 \%$ confluence, the cells were serum-starved overnight in FBS-free DMEM. BSMCs were then stimulated for 24 hours with $5 \mu \mathrm{g} / \mathrm{ml}$ of polyinosinic:polycytidylic acid (polyI: C) (R\&D Systems, Minneapolis, USA) alone or combined with 1,25D3 (100 nM) (Sigma-Aldrich Int, USA) treatment. Both reagents were added simultaneously to the cells. Ethyl alcohol $(\mathrm{EtOH})(0.1 \%)$ vehicle was added to unstimulated BSMCs and used as control for the experiments. After stimulation, the cells were processed for RNA extraction and cell-free culture media were collected and frozen for ELISA experiments.

\section{Quantitative Reverse Transcription- Polymerase Chain Reaction (qRT-PCR)}

Gene expression levels of VDR, CYP24A1, TLR3, IL-6, IFN- $\beta 1$, FN1, COL1A1, and CCL2 were determined in BMSCs groups: 
TABLE 1 | Characteristics of the subjects included in this study.

\begin{tabular}{|c|c|c|c|c|}
\hline \multirow{2}{*}{$\begin{array}{l}\text { Subjects' characteristics } \\
\text { Groups }\end{array}$} & \multicolumn{2}{|c|}{ Asthma } & \multicolumn{2}{|c|}{ COPD } \\
\hline & Non-asthmatics healthy controls & Asthma & Non-COPD healthy controls & COPD \\
\hline Subjects, N & 3 & 4 & 3 & 4 \\
\hline Age, years & $37.8 \pm 9.9$ & $35 \pm 4.4$ & $74 \pm 7$ & $71.7 \pm 4.8$ \\
\hline Disease severity & - & severe & - & mild \\
\hline Smoking status & non-smokers & non-smokers & smokers & smokers \\
\hline Pack years of smoking & - & - & $24.2 \pm 2.4$ & $36.3 \pm 3.1$ \\
\hline Gender, M/F & $2 / 1$ & $1 / 3$ & $2 / 1$ & $2 / 2$ \\
\hline FEV1, \% & ND & ND & $109 \pm 15.3$ & $54.7 \pm 14.7$ \\
\hline FEV1/FVC ratio, \% & ND & ND & $82.8 \pm 7.9$ & $61.4 \pm 7.4$ \\
\hline Medication & none & albuterol, nasal steroids & none & albuterol, nasal steroids \\
\hline
\end{tabular}

FEV1, Forced Expiratory Volume at 1s; FVC, Forced vital capacity; M, male; F, female; ND, not determined. Values are mean \pm SE. Pack years of smoking were calculated by multiplying the number of years smoked by the average number of packs per day.

asthma versus healthy controls and smokers-COPD versus smokers-healthy controls by quantitative real time-PCR (qRTPCR). Real time-PCR primers are listed in Table 2. Briefly, total RNA from BSMCs lysates was extracted using RiboZol reagent (VWR, Leicestershire, UK), as directed by the manufacturer's instructions. Contaminating DNA was removed from $1 \mu \mathrm{g}$ of total RNA using the AccuRT Genomic DNA Removal Kit and reverse transcribed into cDNA using the 5X All-In-One Reverse Transcriptase Master mix, according to the manufacturer's instructions [Applied Biological Materials (abm), Richmond, BC, Canada]. Relative levels of targeted pro-inflammatory and pro-fibrotic genes' mRNA were measured using BrightGreen qRT-PCR Master mix (abm). The qRT-PCR amplification was performed using CFX96 thermal cycler (BioRad, Hercules, USA) according to the manufacturer's protocol (abm, BC, Canada). The gene-specific mRNA primer sequences listed in Table 2 were designed using NCBI Primer3/BLAST software and synthesized by Life Technologies (Invitrogen). Each sample was tested in duplicates and the experiment was performed at least twice. The $2^{-\triangle \Delta C T}$ method was applied to determine the relative fold change in gene expressions in samples treated with polyI:C alone or polyI:C-1,25D3-stimulated BSMCs from asthma/ COPD relative to unstimulated BSMCs from healthy controls, after normalization to the housekeeping gene, Glyceraldehyde 3-phosphate Dehydrogenase $(G A P D H)$, like previously described (24).

\section{Quantification of Pro-Inflammatory and Pro-Fibrotic Markers}

Cell-free supernatants from polyI:C alone or polyI:C-1,25D3stimulated BSMCs were harvested and stored for further cytokine measurements. The following ELISA kits: Human CCL2/MCP-1 DuoSet DY279-05 (R\&D Systems), Human Fibronectin (FN1) DuoSet ELISA DY1918-05 (R\&D Systems), Human IFN-beta DuoSet ELISA DY814-05 (R\&D Systems), and Human IL-6 ELISA MAX Deluxe (Cat. No. 430504, BioLegend) were used. Assay procedure was followed according to the manufacturer's protocol. The limits of detection for all ELISAs' kits were in picogram range $(>7.8 \mathrm{pg} / \mathrm{ml})$, except for fibronectin 1 for which the limit of detection was $>0.1 \mathrm{ng} / \mathrm{ml}$. The absorbance was read at $450 \mathrm{~nm}$ (corrections $570 \mathrm{~nm}$ ) in a microplate reader (Epoch Spectrophotometer System).

\section{Quantification of Intracellular Type I Collagen in BSMCs}

To quantify intracellular type I collagen produced in BSMCs, the anti-human type I collagen antibodies conjugated to fluorescein isothiocyanate (FITC) (Millipore, MAB3262F) and Live/Dead Fixable Violet (ThermoFisher Scientific, L34955) dual staining was performed, according to the manufacturer's instructions. Briefly, polyI:C alone and polyI:C-1,25D3-stimulated BSMCs were harvested using non-enzymatic cell stripper solution

TABLE 2 | Gene specific primer sequences used for qRT-PCR.

\begin{tabular}{|c|c|c|c|c|}
\hline Gene & NCBI Reference & Forward primer (5' to $\left.3^{\prime}\right)$ & Reverse primer (5' to $\left.3^{\prime}\right)$ & Amplicon (bp) \\
\hline GAPDH & NM_002046 & GAAGGTGAAGGTCGGAGT & GAAGATGGTGATGGGATTC & 226 \\
\hline VDR & NM_000376 & CTTCAGGCGAAGCATGAAGC & CCACCATCATTCACACGAACTGG & 128 \\
\hline CYP24A1 & NM_000782 & GCTTCTCCAGAAGAATGCAGGG & CAGACCTTGGTGTTGAGGCTCT & 125 \\
\hline TLR3 & NM_003265 & GCGCTAAAAAGTGAAGAACTGGAT & GCTGGACATTGTTCAGAAAGAGG & 145 \\
\hline IL-6 & NM_000600 & ACCTTCCAAAGATGGCTGAAA & GCTCTGGCTTGTTCCCTCACTAC & 153 \\
\hline IFN- $\beta 1$ & NM_002176 & CTTGGATTCCTACAAAGAAGCAGC & TCСTCСTTCTGGAACTGCTGCA & 146 \\
\hline FN1 & NM_212482 & CCAACTGGTAACCCTTCC & CCAACACTGGGTTGCTGA & 156 \\
\hline COL1A1 & NM_000088 & GATTCCCTGGACCTAAAGGTGC & TCCAGCCTCTCCATCITTGC & 110 \\
\hline CCL2 & NM_002982 & CCCCAGTCACCTGCTGTTAT & TGGAATCCTGAACCCACTTC & 171 \\
\hline
\end{tabular}

GAPDH, Glyceraldehyde 3-phosphate dehydrogenase; VDR, Vitamin D receptor; CYP24A1, cytochrome P450 family 24 subfamily A member 1; TLR3, Toll like receptor 3; IL-6, Interleukin -6; IFN- $\beta 1$, Interferon beta 1; FN1, Fibronectin 1; COL1A1, Collagen type I alpha chain 1; CCL2, Chemokine ligand 2. 
(Corning, Manassas, VA, USA), centrifuged for $5 \mathrm{~min}$ at 500xg and $2 \times 10^{5}$ cells were pre-incubated with Live/Dead dye (1/1000) for 15 minutes at room temperature. Cells were then washed with phosphate-buffered saline (PBS) and fixed with $2 \%$ paraformaldehyde (PFA) for 10 minutes. After PBS washing, the cells were immunolabelled for $1 \mathrm{~h}$ at room temperature with anti-human type I collagen-FITC (1/200) diluted in permeabilization buffer $(0.05 \%$ Triton, $1 \%$ BSA in PBS). Then, the cells were washed with PBS and kept on ice while they were analyzed by flow cytometry (FACSCanto II, BD Biosciences, USA). EtOH (0.1\%) treated and unstained cells served as control samples. Compensation beads (Invitrogen, Ref. 01-2222-41) were stained with anti-human type I collagen-FITC or Pacific Blue Mouse IgG1 isotype control (BD Pharmingen, Cat. 558120) and used as compensation controls, according to the manufacturer's instructions. For each sample, $1 \times 10^{5}$ single cell events were acquired and analyzed by FlowJo 10.0.7 software. Live-cells gating strategy to analyze type I collagen positive cells is shown in Figures 6E-G.

\section{Statistical Analysis}

One-way analysis of variance (ANOVA) coupled with NewmanKeuls post-hoc tests were performed to assess statistical significance between groups. All results are presented as mean \pm standard error (SE) from 2 independent experiments using GraphPad Prism 5 (GraphPad, San Diego, CA, USA). A $p$ value $>0.05$ was considered not statistically significant $(n s)$. The level of significance was set at ${ }^{*} p \leq 0.05,{ }^{* *} p<0.01$, and ${ }^{* *} p<0.001$.

\section{RESULTS}

\section{BSMCs Respond to 1,25D3 by Inducing the Expression of CYP24A1, Regulated by VDR}

To determine whether BSMCs respond functionally to $1,25 \mathrm{D} 3$ treatment, the relative expression of CYP24A1 and VDR were tested by qRT-PCR in polyI:C-stimulated BSMCs, with or without 1,25D3 for 24 hours. CYP24A1 gene expression was significantly upregulated upon addition of $1,25 \mathrm{D} 3$ to polyI:Cstimulated BSMCs, while polyI:C alone had no significant effect. The addition of 1,25D3 to polyI:C-stimulated BSMCs significantly induced CYP24A1 mRNA expression in asthma (5547 \pm 454 -fold increase, $p<0.001$ ) (Figure 1A) and COPD (3565 \pm 311 -fold increase, $p<0.01$ ) (Figure 1B) as compared to control groups. The mRNA expression of VDR was only slightly increased in polyI:C-stimulated BSMCs and this effect was significantly increased by the addition of $1,25 \mathrm{D} 3(0.866 \pm 0.23$ fold increase, $p=0.01$ in asthma (Figure 1C) and 1.6 \pm 0.73 -fold increase in COPD, $p<0.05$ ) (Figure 1D). The effect of $1,25 \mathrm{D} 3$ treatment alone in BSMCs was also investigated. We observed statistically significant increase in mRNA CYP24A1 and VDR expression $(p<0.05)$ when $1,25 \mathrm{D} 3$ alone was added to the cells and this effect was observed at a higher extent in diseased BSMCs as compared to non-diseased BSMCs, (Figures 1A-D).

\section{1,25D3 Decreases the Expression of TLR3 Activated in Response to Polyl:C}

Since TLR3 activation is required for polyI:C-induced proinflammatory and pro-fibrotic mediators release, we further investigated whether $1,25 \mathrm{D} 3$ treatment influences TLR3 expression in BSMCs. Stimulation of BSMCs with polyI:C (5 $\mathrm{ug} / \mathrm{ml}$ ) for 24 hours significantly induced mRNA expression of TLR3, in asthma (6.047 \pm 0.924 -fold increase, $p<0.05)$ (Figure 2A) and COPD (9.878 \pm 0.779 -fold increase, $p<$ 0.001) (Figure 2B) as compared to control groups. While Addition of $1,25 \mathrm{D} 3$ to polyI:C-stimulated BSMCs significantly decreased TLR3 expression, in asthma (1.743 \pm 0.6387-fold decrease, $p<0.05)$ (Figure 2A) and COPD (4.495 \pm 0.6318fold decrease, $p<0.05$ ) (Figure $2 \mathbf{B}$ ) as compared to control groups. On the contrary, $1,25 \mathrm{D} 3$ treatment alone had no statistically significant effect $(p>0.05)$ on TLR3 mRNA expression in BSMCs, (Figures 2A, B).

\section{1,25D3 Decreases Polyl:C-Induced Release of Pro-Inflammatory and Pro-Fibrotic Markers in BSMCs}

Based on our dose-response experiments (data not shown), polyI: $\mathrm{C}$ at $5 \mu \mathrm{g} / \mathrm{ml}$ was considered optimal and used to determine the pro-inflammatory and pro-fibrotic responses in BSMCs. Because $1,25 \mathrm{D} 3$ has anti-inflammatory and anti-fibrotic effects, we hypothesized that $1,25 \mathrm{D} 3$ treatment decreases the proinflammatory and pro-fibrotic responses in polyI:C-stimulated BSMCs. Therefore, BSMCs were stimulated with polyI:C (5 $\mu \mathrm{g} /$ $\mathrm{ml}$ ) alone or in combination with 1,25D3 (100 nM) for 24 hours. Following stimulation, BSMCs were collected, and RNA was extracted. As shown in Figures 3A-F, BSMCs treated with polyI: $\mathrm{C}$, had a significant increase in mRNA expression of $I L-6, I F N-\beta 1$, CCL2 compared to untreated cells and this effect was observed to a higher extent in asthma and COPD BSMCs $(p<0.05)$. When $1,25 \mathrm{D} 3$ was added to polyI:C-stimulated BSMCs, there was a significant decrease in mRNA expression of IL-6, IFN- $\beta 1$, CCL2. In addition, we observed a higher extent of the anti-inflammatory effect of 1,25D3 in BSMCs from COPD, namely for IL-6 (40.24 \pm 15.39 -fold decrease, $p<0.05$, Figure 3B) and IFN- $\beta 1$ (6.65 \pm 2.21 fold decrease, $p<0.01$, Figure 3D), than in BSMCs from asthma (Figures 3A, C, Table S1A). The intra- and inter-group relative fold change differences in the expression of pro-inflammatory and pro-fibrotic markers among groups are described in the Supplementary Data (Tables S1A and B).

To confirm these findings, ELISA was performed on conditioned media obtained from BSMCs stimulated with polyI:C or polyI:C-1,25D25, and protein levels of IL-6, IFN- $\beta 1$ and MCP-1 were assessed. Similarly, polyI:C stimulation significantly increased IL- 6 and MCP-1 protein levels in asthmatic and COPD compared to control groups (Figures 4A-D and Table S1A). A significant overall decrease in the protein levels of IL-6 and MCP-1 (Figures 4A-D and Table S1B) was detected upon the addition of 1,25D3 to polyI:Cstimulated BSMCs. Furthermore, an increased antiinflammatory effect of 1,25D3 was observed in BSMCs from COPD, for secreted IL-6 (954 \pm 217-fold decrease, $p<0.001$, 
A

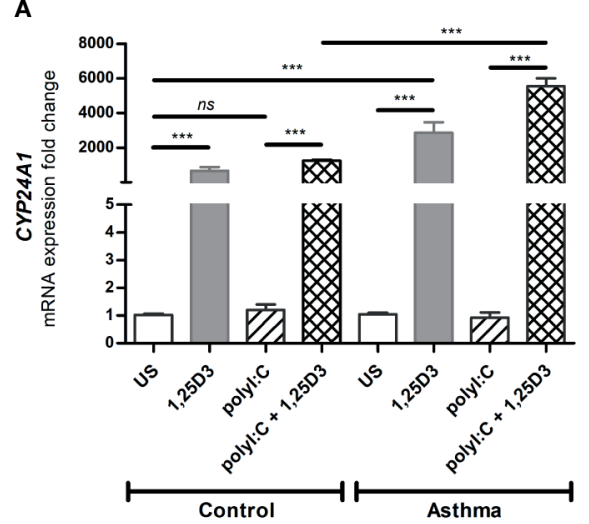

C

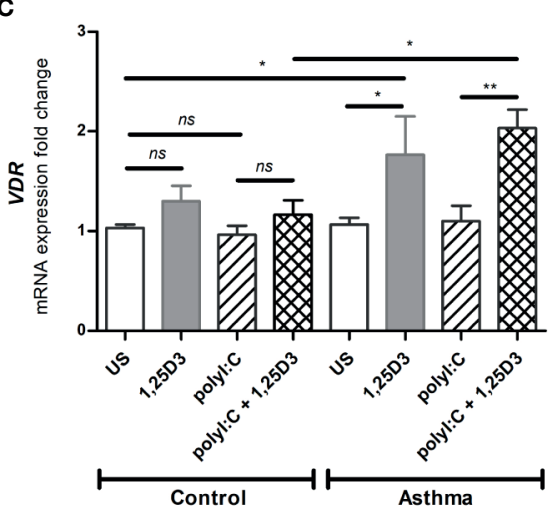

B

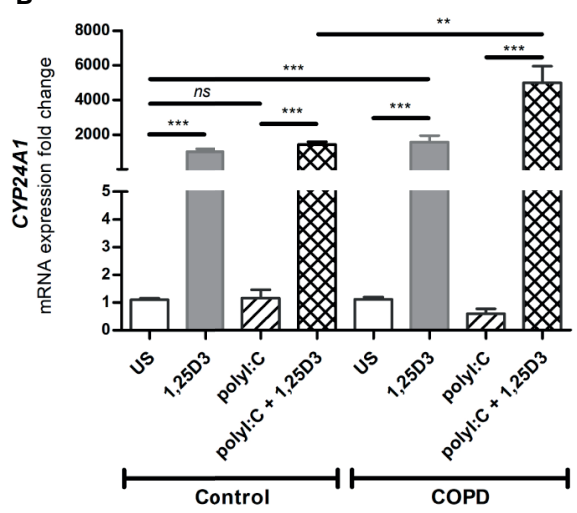

D

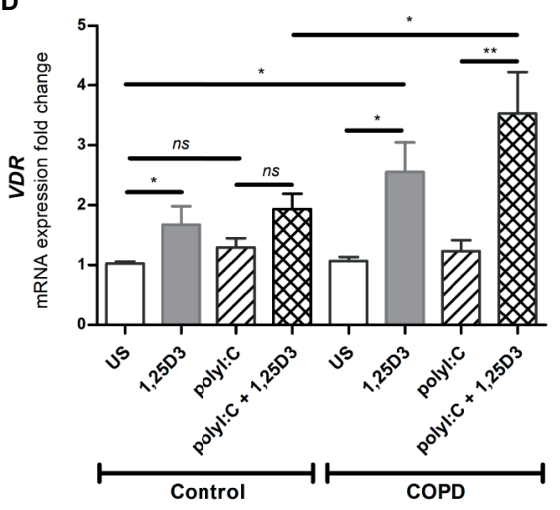

FIGURE 1 | mRNA expression of CYP24A1 (A, B) and VDR (C, D) in BSMCs from asthma (A, C) and COPD (B, D) compared to BSMCs from healthy control groups. $n=4$ asthma, $n=3$ healthy controls, $n=4$ COPD, and $n=3$ healthy control smokers. qRT-PCR data is representative of two independent experiments. One way ANOVA using Newman-Keuls multiple comparison test were performed to assess statistical significance between groups. Mean \pm SE; $(n s) p>0.05$, no significant difference, ${ }^{*} p<0.05,{ }^{* *} p<0.01,{ }^{* \star *} p<0.001$.
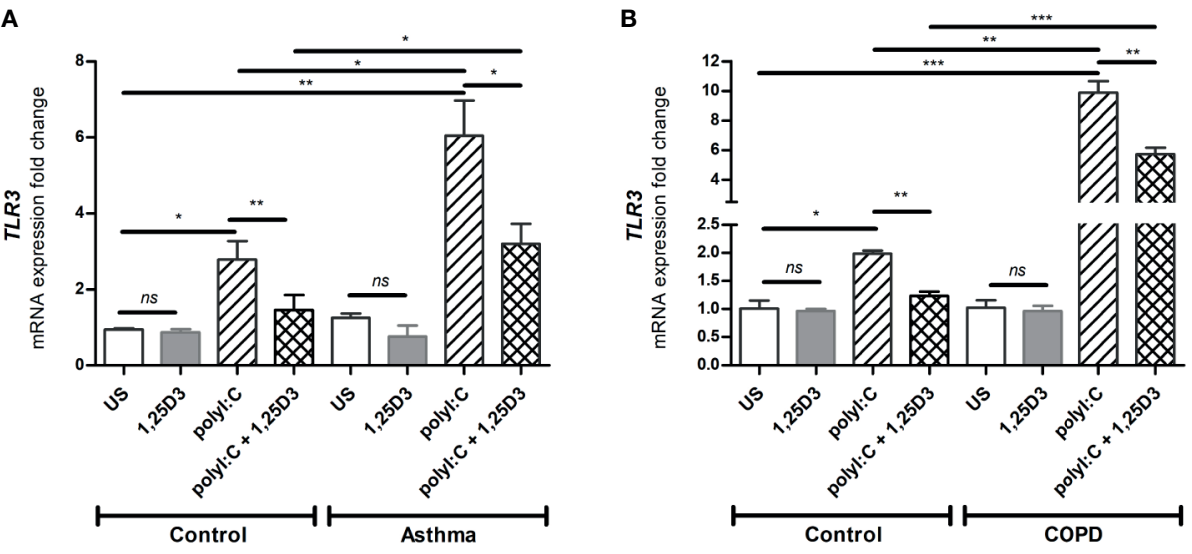

FIGURE 2 mRNA expression of TLR3 in asthma (A) and COPD (B) compared to healthy control groups. $n=4$ asthma, $n=3$ healthy controls, $n=4$ COPD, and $n=3$ healthy control smokers. QRT-PCR data is representative of two independent experiments. One way ANOVA using Newman-Keuls multiple comparison test were performed to assess statistical significance between groups. Mean $\pm \mathrm{SE} ;(n s) p>0.05$, no significant difference, ${ }^{\star} p<0.05,{ }^{* *} p<0.01,{ }^{* \star *} p<0.001$. 
Presa et al.

1,25D3 Role in TLR3 Responses

A

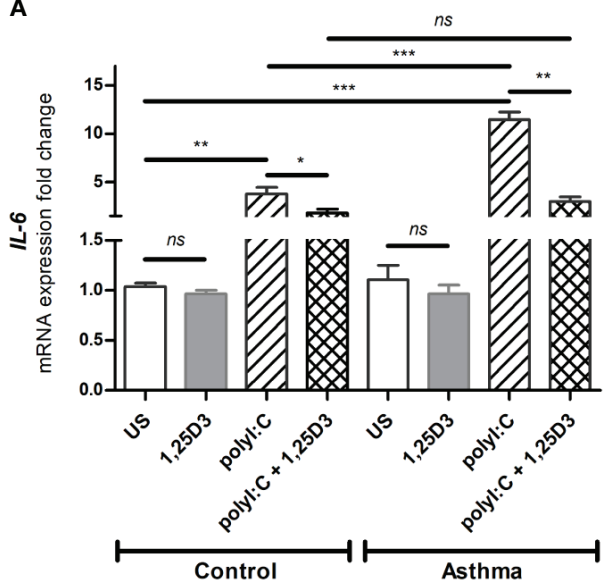

C
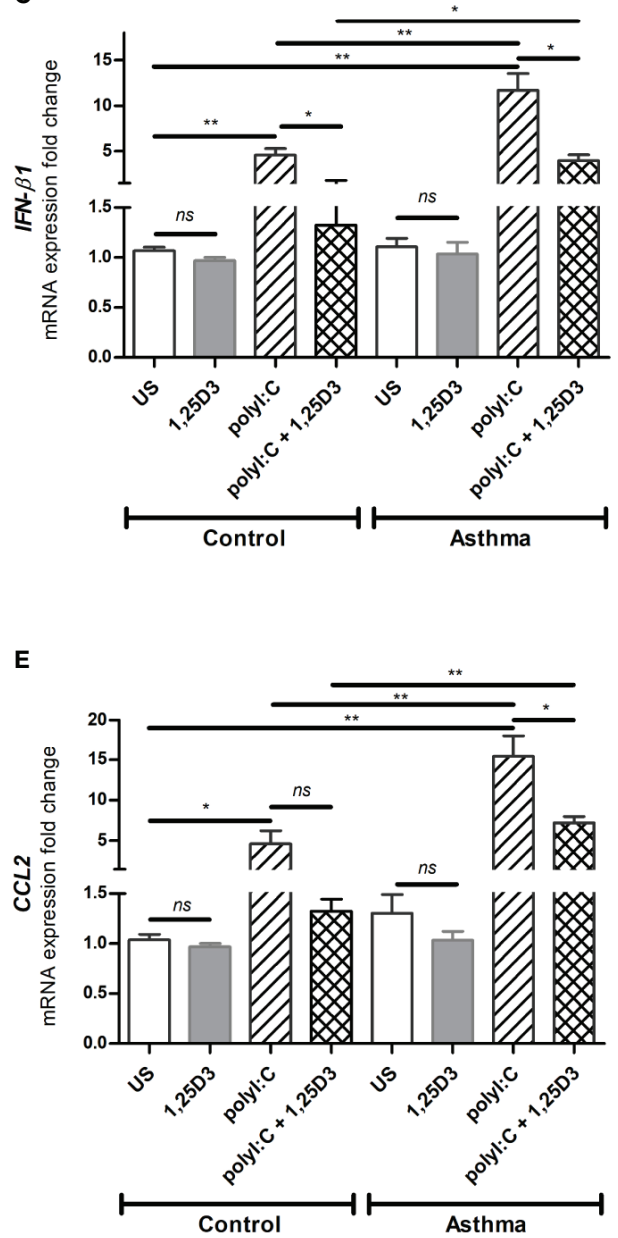

B

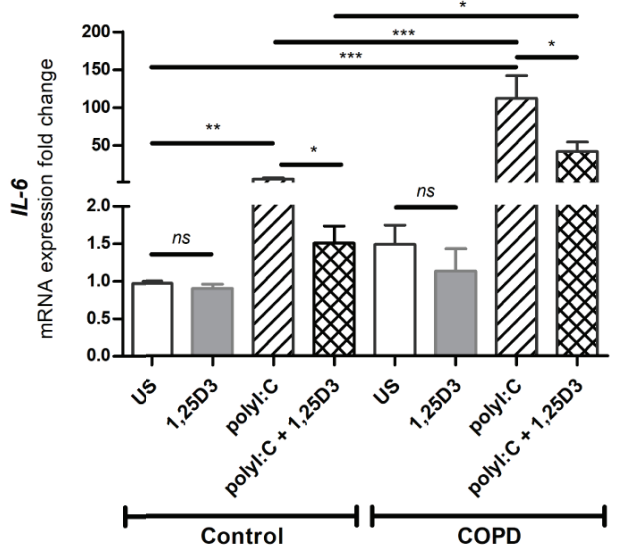

D

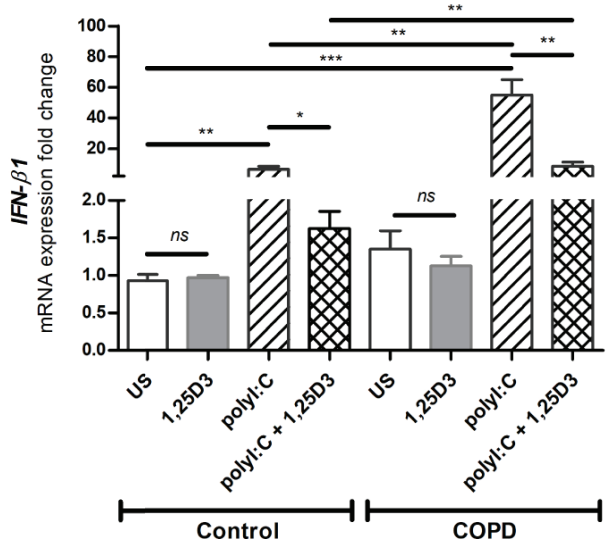

$\mathbf{F}$

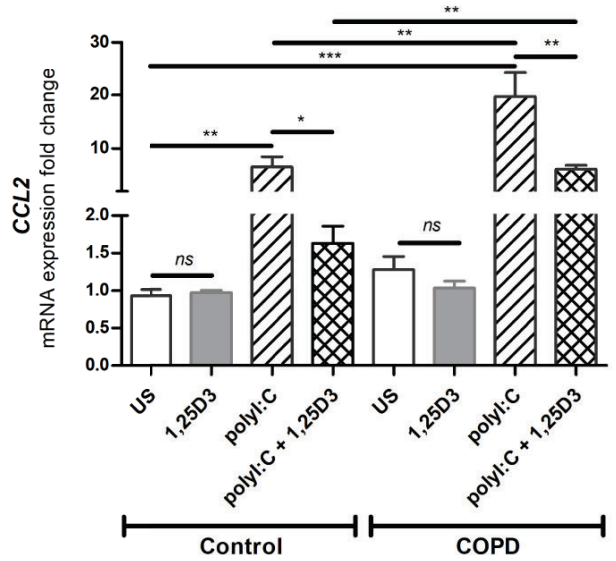

FIGURE 3 | mRA expression of IL-6 (A, B), IFN- $\beta 1$ (C, D) and CCL2 (E, F) in BSMCs from severe asthma (A, C, E) and mild COPD (B, D, F) compared to BSMCs from healthy control groups. $n=4$ asthma, $n=3$ healthy controls, $n=4$ COPD, and $n=3$ healthy control smokers. qRT-PCR data is representative of two independent experiments. One way ANOVA using Newman-Keuls multiple comparison test were performed to assess statistical significance between groups. Mean \pm SE; (ns) $p>0.05$, no significant difference, ${ }^{\star} p<0.05,{ }^{\star \star} p<0.01,{ }^{\star \star \star} p<0.001$.

Frontiers in Immunology | www.frontiersin.org

6

August 2021 | Volume 12 | Article 715848 

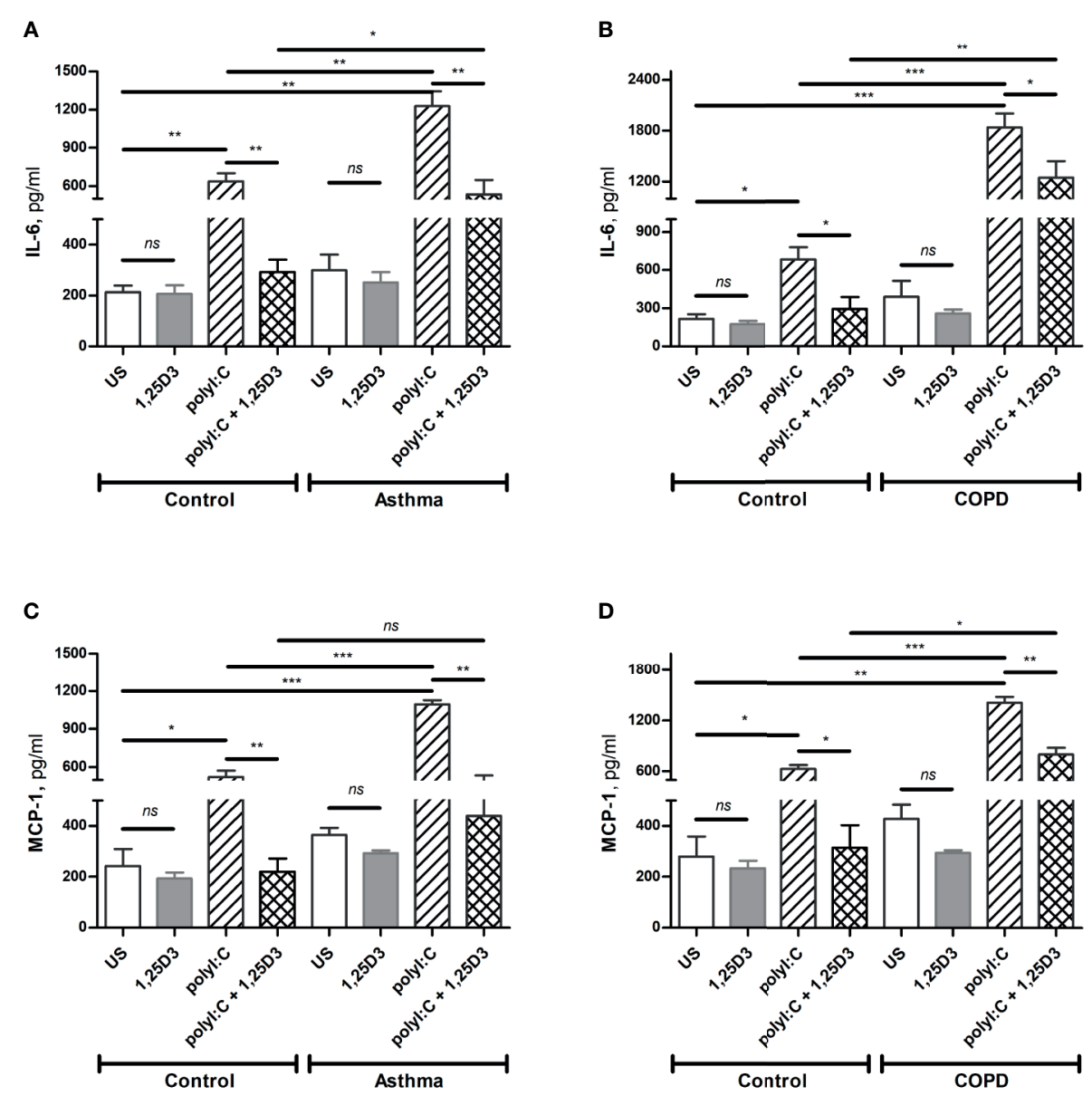

FIGURE 4 | Protein levels of IL-6 (A, B), and MCP-1 (C, D) in BSMCs from asthma (A, C) and COPD (B, D) compared to BSMCs from healthy control groups were quantified by ELISA. $n=4$ asthma, $n=3$ healthy controls, $n=4$ COPD, and $n=3$ healthy control smokers. Data is representative of two independent experiments. One way ANOVA using Newman-Keuls multiple comparison test were performed to assess statistical significance between groups. Mean \pm SE; (ns) $p>0.05$, no significant difference, ${ }^{\star} p<0.05,{ }^{* \star} p<0.01,{ }^{\star \star *} p<0.001$.

Figure 4B) and MCP-1 (488.9 \pm 120 -fold decrease, $p<0.01$, Figure 4D and Table S1A) than in BSMCs from asthma (Figures 4A, C and Table S1A). However, we could not validate the mRNA data for IFN- $\beta 1$ by ELISA assay, since the protein levels of IFN- $\beta 1$ were under the detection limit $(<7.8 \mathrm{pg} / \mathrm{ml})$ (data not shown).

To test whether TLR3 activation might control the expression of pro-fibrotic genes, mRNA expression of FN1 and COL1A1 were assessed in polyI:C alone or polyI:C-1,25D3-stimulated BSMCs. BSMCs treated with polyI:C alone displayed an increase in the mRNA expression of FN1 and COL1A1 compared to untreated cells (Figures 5A-D), and this effect was observed to a higher extent in asthma and COPD as compared to control groups $(p<0.05)$ (Figures 5A-D and Table S1A). 1,25D3 treatment significantly decreased polyI:Cinduced mRNA expression of FN1 and COL1A1, as described in Table S1B. Increased anti-fibrotic effect of 1,25D3 was observed in BSMCs from asthma (Figures 5A, C and Table S1A; FN1 average fold-decrease $6.78 \pm 0.65, p<0.001$; COL1A1 average fold-decrease $3.68 \pm 1.21, p<0.05 p=0.014)$ compared to BSMCs from COPD (Figures 5B, D and Table S1A). Similarly, 1,25D3 treatment significantly decreased protein levels of FN1 and mean number of the type I collagen positive cells in polyI:Cstimulated BSMCs, to a greater extent in asthma (Figures 6A, C and Table S1A; fibronectin 1 average fold-decrease $263 \pm 94, p<$ 0.05 ; type I collagen average fold-decrease $20.67 \pm 3.77 p<0.01$ ) than in COPD (Figures 6B, D and Table S1A. While an overall decrease in mRNA expression and protein levels of proinflammatory (Figures $\mathbf{3 A}-\mathbf{F}$ and $\mathbf{4 A - D}$ ) and pro-fibrotic markers (Figures $\mathbf{5 A - D}$ and $\mathbf{6 A - D}$ ) was observed upon the addition of 1,25D3 alone to BSMCs, the effect observed was not statistically significant $(p>0.05)$. Although not statistically significant, we observed an increased overall mRNA expression of pro-inflammatory and pro-fibrotic markers at the baseline in unstimulated-BSMCs from asthma (Figures 3A, C, E and 5A, C) and COPD (Figures $\mathbf{3 B}, \mathbf{D}, \mathbf{F}$ and $\mathbf{5 B}, \mathbf{D}$ ) compared to unstimulated-BSMCs from healthy control groups. Similarly, we observed an increased overall protein level of 

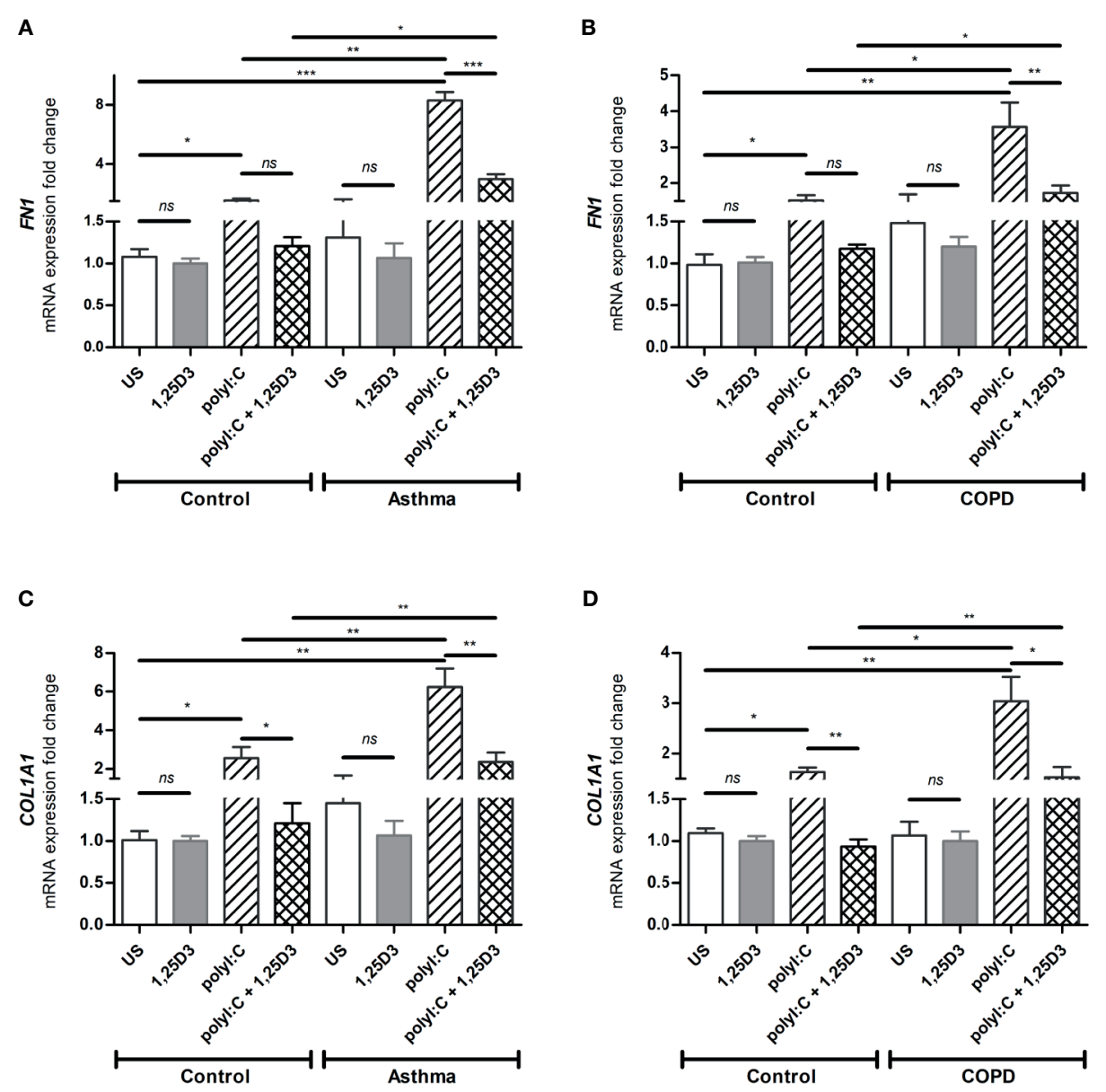

FIGURE 5 | mRNA expression of FN1 (A, B) and COL1A1 (C, D) in BSMCs from asthma (A, C) and COPD (B, D) compared to BSMCs from healthy control groups. $n=4$ asthma, $n=3$ healthy controls, $n=4$ COPD, and $n=3$ healthy control smokers. qRT-PCR data is representative of two independent experiments. One way ANOVA using Newman-Keuls multiple comparison test were performed to assess statistical significance between groups. Mean \pm SE; (ns) $p>0.05$, no significant difference, ${ }^{*} p<0.05,{ }^{\star *} p<0.01,{ }^{\star \star *} p<0.001$.

pro-inflammatory and pro-fibrotic markers at the baseline in unstimulated-BSMCs from asthma (Figures 4A, C and 6A, C) and COPD (Figures $4 \mathbf{B}, \mathbf{C}$ and $\mathbf{6 B}, \mathbf{D}$ ) compared to unstimulated-BSMCs from healthy control groups.

\section{DISCUSSION}

Abnormal immune responses in viral infections may worsen acute lung injury, increasing airflow obstruction or pulmonary fibrosis, and pathological conditions already existent in patients with asthma or COPD.

In the present study, we have demonstrated the effect of vitamin D3 supplementation on viral-induced TLR3 responses in Bronchial Smooth Muscle Cells (BSMCs), as a mechanism contributing to pulmonary fibrosis in asthma and COPD. Polyinosinic: polycytidylic acid (polyI:C), a synthetic analog of viral double-stranded RNA, has been previously described in driving viral immunomodulatory response (25) and dermal fibrosis (14) in cultured fibroblasts through the activation of TLR3 receptors. Although fibroblasts are the major contributors to airway remodeling in asthma and COPD, other cell types within the lung, including smooth muscle cells are also involved. On the other hand, vitamin D3 through its active metabolite $1,25 \mathrm{D} 3$, is known to possess anti-inflammatory and anti-fibrotic mechanisms (26-28), and have shown to improve immune responses $(29,30)$. Therefore, we investigated the role of $1,25 \mathrm{D} 3$ in polyI:C-induced pro-inflammatory and pro-fibrotic responses in primary BSMCs isolated from subjects with asthma and COPD. The BSMCs used in this study were age-matched for asthma experiments, while for COPD experiments, in addition to age, smoking history was also considered. Cigarette smoke, a highly prevalent risk factor in COPD, is also known to alter the expression and function of TLR3 receptors (31). Our findings indicated that pro-inflammatory and pro-fibrotic mediators are increased at the baseline in BSMCs from both asthma and COPD, and that TLR3 agonist polyI:C, significantly upregulated $I L-6, I F N-\beta 1, C C L 2, F N 1$ and $C O L 1 A 1$ expressions 

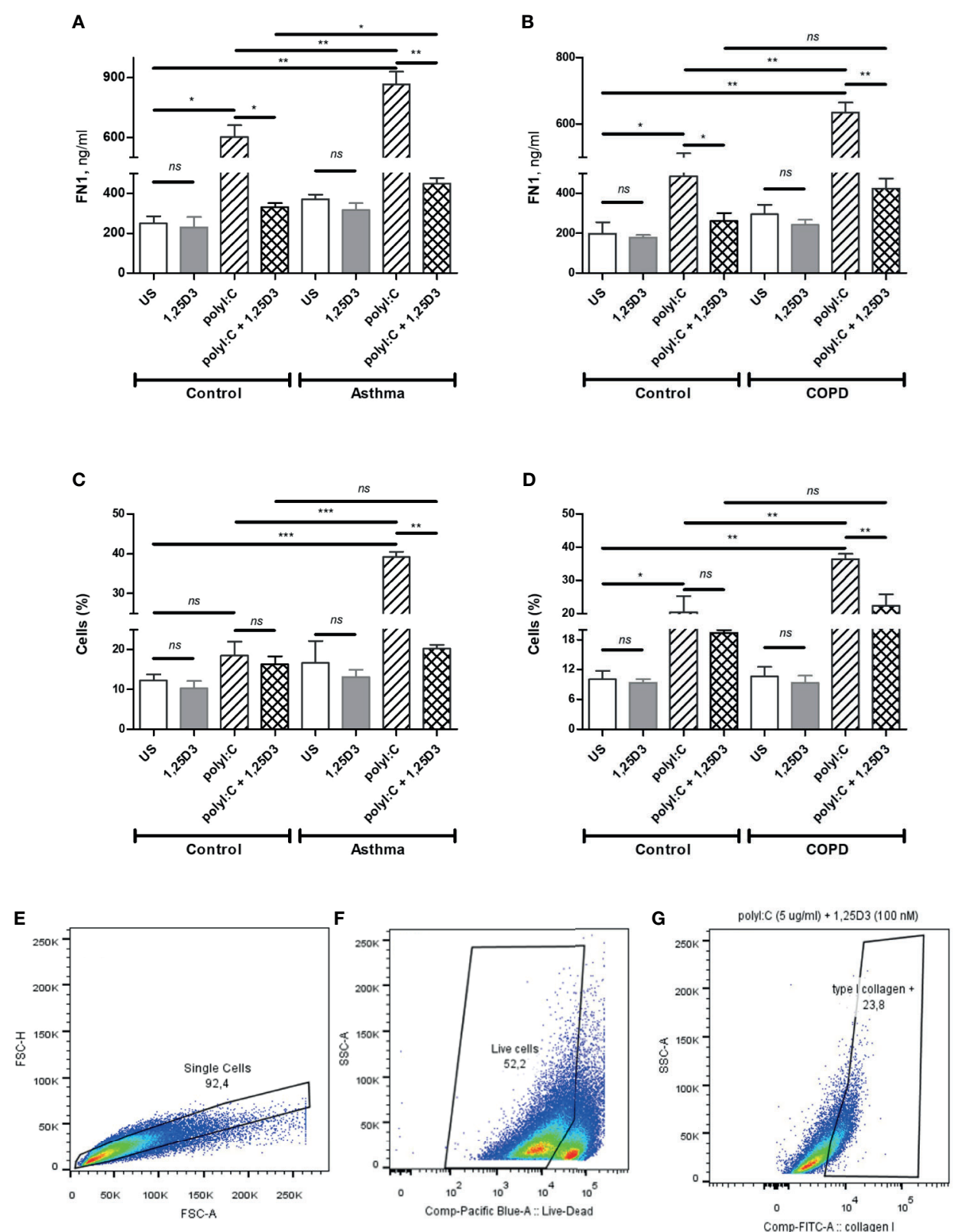

FIGURE 6 | Protein levels of FN1 in BSMCs from asthma (A) and COPD (B) compared to BSMCs from healthy control groups were quantified by ELISA. Flow Cytometry was used to quantify intracellular levels of type I collagen in BSMCs from asthma (C) and COPD (D) groups. Graphic quantitation, \% of type I collagen positive BSMCs populations using GraphPad (C, D). Gating strategy of type I collagen positive BSMCs: (E) Exclusion of doublet events. (F) Exclusion of dead cells. (G) Gating of type I collagen positive BSMCs. The number of cells (\%) included in each gate is indicated in each panel. $n=4$ asthma, $n=3$ healthy controls, $n=4$ COPD, and $n=3$ healthy control smokers. Data is representative of two independent experiments. One way ANOVA using Newman-Keuls multiple comparison test were performed to assess statistical significance between groups. Mean \pm SE; $(n s) p>0.05$, no significant difference, ${ }^{*} p<0.05$, ${ }^{* \star} p<0.01,{ }^{* \star *} p<0.001$.

in BSMCs (Figures $\mathbf{3 A - F}$ and $\mathbf{5 A - D}$ ). The selected markers in this study represent pro-inflammatory and pro-fibrotic gene signatures in both viral infections, and in chronic respiratory diseases. Our findings were further supported by demonstrating the significant downregulation of these markers upon 1,25D3, in polyI:C-stimulated BSMCs, in the context of asthma and COPD when compared to control groups.
To gain a mechanistic insight into the effect of vitamin D3 on the activation and functionality of vitamin D receptors (VDR) in BSMCs, the effects of 1,25D3 supplementation of polyI:Cstimulated BSMCs was investigated. We observed a significant increase in the mRNA expression of CYP24A1 when 1,25D3 was added to the polyI:C stimulated BSMCs, whereas polyI:C alone slightly altered its mRNA expression (Figures 1A, B). 
Cytochrome P450 family 24 subfamily A member 1 (CYP24A1) encodes 24-hydroxylase, an enzyme that regulates vitamin D metabolism through a negative feedback loop activation, thereby regulating its own metabolism (32). This result was therefore expected since CYP24A1 is highly upregulated by $1,25 \mathrm{D} 3$ through a VDR-dependent mechanism. The mRNA expression of $V D R$ was also increased when $1,25 \mathrm{D} 3$ was added to polyI:C stimulated BSMCs (Figure 1C, D). Moreover, our data revealed an increased mRNA expression of TLR3 in polyI:C-stimulated BSMCs, and this effect was significantly diminished after 1,25D3 treatment (Figures 2A, B). Interestingly, we observed a higher grade of $V D R$ and TLR3 activation in BSMCs from subjects with asthma and COPD when compared with controls (Figures 1C, D and $\mathbf{2 A}, \mathbf{B}$ ). These data suggest that BSMCs express functional $V D R$ and TLR3, and that BSMCs from diseased groups (asthma and COPD) may have increased sensitivity to polyI:C than BSMCs from control groups.

Previous studies have shown that BSMCs express TLRs (10, 33), including TLR3, which may indicate their ability to respond to innate immune stimuli and a possible role in viral-induced inflammatory exacerbations. Although TLR3 agonists are well known to stimulate type I interferons (IFN- $\alpha$ and IFN- $\beta 1$ ), their activation also results in upregulation of a variety of NF-kB regulated pro-inflammatory cytokines and chemokines, including $I L-6, I L-8$, tumor necrosis factor alpha $(T N F-\alpha)$ and CCL2 (34). Our data also demonstrated an increased mRNA expression of $I L-6, I F N-\beta 1$ and CCL2 in polyI:C-stimulated BSMCs from diseased groups when compared with controls (Figures 3A-F), and this increase was observed to a significantly greater extent in COPD cells (Figures 3B, D, F). Moreover, cell culture media obtained from polyI:C-stimulated BSMCs showed increased IL- 6 and MCP-1 protein secretion, while 1,25D3 treatment significantly attenuated their levels (Figures 4A-D). While we noticed, prior to stimulation, an increased baseline level of these pro-inflammatory cytokines in BSMCs from diseased groups, the effect observed was not statistically significant. These data suggest that BSMCs from asthma and COPD are more prone to develop an inflammatory and fibrotic phenotype than the controls. These data suggest that polyI:C-stimulation leads to enhanced inflammatory responses in BSMCs from diseased groups, and that 1,25D3 acts on TLR3 to modulate the pro-inflammatory responses in polyI:Cstimulated BSMCs. Our data also points towards a more effective anti-inflammatory effect of $1,25 \mathrm{D} 3$ in polyI:Cstimulated BSMCs from subjects with COPD when compared to asthma (Table S1A). This pattern in response to $1,25 \mathrm{D} 3$ treatment could be beneficial, particularly during the initial stage of viral infection, therefore limiting the amount of proinflammatory mediators and protecting the lung tissue from further damage. Interestingly, we observed a lack of IFN- $\beta 1$ secretion (as measured by ELISA, data not shown) and this result was unpredicted since the mRNA expression of IFN- $\beta 1$ was highly upregulated in polyI:C-stimulation BSMCs (Figures 3C, D). This is supported by a previous study, where Mazaleuskaya et al. provided evidence of high expression levels of IFN- $\beta 1$ in polyI:C-stimulated murine macrophages at $24 \mathrm{~h}$, but the secreted
IFN- $\beta 1$ was only detected at $6 \mathrm{~h}$ post stimulation (25). Taken together, these results suggest that IFN- $\beta 1$ response in cells is regulated differentially in time post transcriptionally and that the levels of IFN- $\beta 1$ should be determined at shorter intervals than $24 \mathrm{~h}$ post-stimulation. In agreement with this, another study mentioned negative regulation of IFN- $\beta 1$ production through transcriptional inactivation of IRF3, which may play a protective role reducing exaggerated inflammatory immune responses and limiting the duration of IFN- $\beta 1$ activation in the host cells during persistent virus infection (35).

In addition, we aimed to establish whether polyI:Cstimulation of BSMCs also increased the mRNA expression and protein levels of FN1 and type I collagen, two pro-fibrotic mediators highly expressed in the airways of asthma and COPD patients. The mechanism by which viral infections cause lung fibrosis is not fully understood. It has been suggested that multiple inflammatory pathways are activated during viral infections, which interplay with the major contributors in lung fibrosis, such as transforming growth factor beta (TGF- $\beta$ ) Smad signaling, and the ECM turnover mechanisms in asthma and COPD $(14,36)$. Our data showed, prior to polyI:C stimulation, an increased basal expression of FN1 and COL1A1 in BSMCs from diseased groups, although this finding did not reach statistical significance. Following polyI:C-stimulation, the mRNA expression and protein levels of FN1 and COL1A1 were increased in BSMCs and 1,25D3 treatment significantly decreased their levels (Figures 5A-D). Interestingly, under polyI: C stimulation, BSMCs from subjects with asthma (Figures 5A, C and Table S1A) were more prone to a pro-fibrotic phenotype compared to BSMCs from COPD subjects (Figures 5B, D and Table S1A). Similarly, the level of fibronectin 1 and type I collagen was increased in polyI:C-stimulated BSMCs compared to unstimulated BSMCs, and 1,25D3 treatment significantly attenuated their levels (Figures 6A-D). Interestingly, 1,25D3 treatment alone showed limited effect on the expression and protein levels of pro-inflammatory and pro-fibrotic fibrotic markers in BSMCs without prior stimulation with polyI:C, as shown previously by other groups (22).

Study limitations. From the clinical data, patients with severe asthma or COPD are predisposed to severe lung injury and presented an increased risk of fibrosis compared to mild-tomoderate illnesses. The main limitation to this study is that BSMCs from COPD group were exclusively from subjects with mild COPD because of sample availability. However, it is also known that subjects with mild COPD presented underlying inflammation in the airways and are at increased risk of respiratory infections compared to healthy subjects $(37,38)$. Another limit of the study was that no available data on the vitamin D status or supplements or additional medication for the subjects included in this study, as this information is not available from the supplier.

Recent clinical evidence identified COPD and asthma as comorbidities in COVID-19 infections, and patients with severe COVID-19 infection have extensive pulmonary fibrotic tissue, in addition to an enhanced inflammatory state (39-41). Although TLR3 activation is triggered by double-stranded (ds) 
RNA motifs, produced during the replication of positive-singlestranded RNA viruses, such as SARS-CoV-2, there are no research studies to demonstrate converging pathways between SARS-CoV-2 receptor and PRRs.

In conclusion, our findings demonstrated that TLR3 agonist polyI:C induce pro-inflammatory and pro-fibrotic responses in BSMCs and suggest their potential for deregulation of the pathways involved in fibrotic responses. Moreover, we have demonstrated that $1,25 \mathrm{D} 3$ by VDR-TLR3 dependent pathways, significantly reduced the pro-inflammatory and pro-fibrotic effects in polyI:C-stimulated BSMCs, indicating a protective function of $1,25 \mathrm{D} 3$ in patients with chronic respiratory conditions and viral infections. Further research is required to shed the light on the interplay between SARS-CoV-2, PRRs and other lung cell types, in the context of 1,25D3 supplementation as a potential antiviral adjuvant therapy in COVID-19 patients with asthma and COPD.

\section{DATA AVAILABILITY STATEMENT}

All datasets generated for this study are included in the article/ Supplementary Material.

\section{ETHICS STATEMENT}

The studies involving human participants were reviewed and approved by Human Research Ethics Board of the University of Manitoba. The patients/participants provided their written informed consent to participate in this study.

\section{AUTHOR CONTRIBUTIONS}

MP performed experiments, analyzed the data, and drafted the manuscript. MG and AM contributed to data analysis and manuscript preparation. NJ participated in the revision of the manuscript. AH provided BSMCs from healthy smokers and COPD subjects and participated in the revision of the manuscript. SA advised throughout the study development and participated in the revision of the manuscript. QH contributed to

\section{REFERENCES}

1. James AL, Elliot JG, Jones RL, Carroll ML, Mauad T, Bai TR, et al. Airway Smooth Muscle Hypertrophy and Hyperplasia in Asthma. Am J Respir Crit Care Med (2012) 185(10):1058-64. doi: 10.1164/rccm.201110-18490C

2. Hogg JC. Pathophysiology of Airflow Limitation in Chronic Obstructive Pulmonary Disease. Lancet (2004) 364(9435):709-21. doi: 10.1016/S01406736(04)16900-6

3. Damera G, Panettieri RA. Does Airway Smooth Muscle Express an Inflammatory Phenotype in Asthma? Br J Pharmacol (2011) 163(1):68-80. doi: 10.1111/j.1476-5381.2010.01165.x

4. Jones RL, Noble PB, Elliot JG, Mitchell HW, McFawn PK, Hogg JC, et al. Airflow Obstruction Is Associated With Increased Smooth Muscle Extracellular Matrix. Eur Respir J (2016) 47(6):1855-7. doi: 10.1183/ 13993003.01709-2015 the design of the experiments and participated in the revision of the manuscript. All authors contributed to the article and approved the submitted version.

\section{FUNDING}

This research was funded by the Richard and Edith Strauss Foundation.

\section{ACKNOWLEDGMENTS}

We would like to thank Dr. S Bhattarai for the expert assistance in flow cytometry. We would also like to thank Dr Ramakrishnan R. for critical reading of this manuscript.

\section{SUPPLEMENTARY MATERIAL}

The Supplementary Material for this article can be found online at: https://www.frontiersin.org/articles/10.3389/fimmu.2021. 715848/full\#supplementary-material

Supplementary Table 1A | Inter-group comparisons: BSMCs from healthy controls versus BSMCs from asthma subjects; BSMCs from healthy control smokers versus BSMCs from COPD subjects. Mean difference in mRNA expression of IL-6, IFN- $\beta 1, C C L 2, F N 1$ and COL1A1 was quantified by qRT-PCR. Cell-free culture media was used for protein quantification by ELISA for IL-6, MCP-1, and fibronectin 1. The intracellular quantification of type I collagen in BSMCs was performed by Flow cytometry. Data are represented as mean \pm SE relative to the control and representative of two independent experiments. One way ANOVA using Newman-Keuls multiple comparison test were performed to assess statistical significance between groups. $p>0.05$, no significant difference.

Supplementary Table 1B | Intra-group comparisons: BSMCs from healthy controls and BSMCs from asthma subjects; BSMCs from healthy control smokers and BSMCs from COPD subjects. Mean difference in mRNA expression of IL-6, IFN- $\beta 1, C C L 2, F N 1$ and COL1A1 was quantified by qRT-PCR. Cell-free culture media was used for protein quantification by ELISA for IL-6, MCP-1, and fibronectin 1. The intracellular quantification of type I collagen in BSMCs was performed by Flow cytometry. Data are represented as mean \pm SE relative to the control and representative of two independent experiments. One way ANOVA using NewmanKeuls multiple comparison test were performed to assess statistical significance between groups. $p>0.05$, no significant difference.
5. Yan F, Gao H, Zhao H, Bhatia M, Zeng Y. Roles of Airway Smooth Muscle Dysfunction in Chronic Obstructive Pulmonary Disease. J Transl Med (2018) 16(1):262. doi: 10.1186/s12967-018-1635-Z

6. Britto CJ, Brady V, Lee S, Dela Cruz CS. Respiratory Viral Infections in Chronic Lung Diseases. Clin Chest Med (2017) 38(1):87-96. doi: 10.1016/j.ccm.2016.11.014

7. Kawai T, Akira S. The Role of Pattern-Recognition Receptors in Innate Immunity: Update on Toll-Like Receptors. Nat Immunol (2010) 11(5):37384. doi: $10.1038 /$ ni. 1863

8. Bell JK, Askins J, Hall PR, Davies DR, Segal DM. The dsRNA Binding Site of Human Toll-Like Receptor 3. Proc Natl Acad Sci USA (2006) 103(23):8792-7. doi: 10.1073/pnas.0603245103

9. Weber F, Wagner V, Rasmussen SB, Hartmann R, Paludan SR. DoubleStranded RNA Is Produced by Positive-Strand RNA Viruses and DNA Viruses But Not in Detectable Amounts by Negative-Strand RNA Viruses. J Virol (2006) 80(10):5059-64. doi: 10.1128/JVI.80.10.5059-5064.2006 
10. Sukkar MB, Xie S, Khorasani NM, Kon OM, Stanbridge R, Issa R, et al. Toll-Like Receptor 2, 3, and 4 Expression and Function in Human Airway Smooth Muscle. J Allergy Clin Immunol (2006) 118(3):641-8. doi: 10.1016/j.jaci.2006.05.013

11. Yamamoto M, Sato S, Hemmi H, Hoshino K, Kaisho T, Sanjo H, et al. Role of Adaptor TRIF in the MyD88-Independent Toll-Like Receptor Signaling Pathway. Science (2003) 301(5633):640-3. doi: 10.1126/science.1087262

12. Jiang Z, Mak TW, Sen G, Li X. Toll-Like Receptor 3-Mediated Activation of NF-KappaB and IRF3 Diverges at Toll-IL-1 Receptor Domain-Containing Adapter Inducing IFN-Beta. Proc Natl Acad Sci USA (2004) 101(10):3533-8. doi: 10.1073/pnas.0308496101

13. Huang C, Wang Y, Li X, Ren L, Zhao J, Hu Y, et al. Clinical Features of Patients Infected With 2019 Novel Coronavirus in Wuhan, China. Lancet (2020) 395(10223):497-506. doi: 10.1016/S0140-6736(20)30183-5

14. Farina GA, York MR, Di Marzio M, Collins CA, Meller S, Homey B, et al. Poly (I:C) Drives Type I IFN- and TgfB-Mediated Inflammation and Dermal Fibrosis Simulating Altered Gene Expression in Systemic Sclerosis. J Invest Dermatol (2010) 130(11):2583-93. doi: 10.1038/jid.2010.200

15. Wigén J, Löfdahl A, Bjermer L, Elowsson-Rendin L, Westergren-Thorsson G. Converging Pathways in Pulmonary Fibrosis and Covid-19 - The Fibrotic Link to Disease Severity. Respir Med X (2020) 2:100023. doi: 10.1016/j.yrmex.2020.100023

16. Pfeffer PE, Hawrylowicz CM. Vitamin D in Asthma: Mechanisms of Action and Considerations for Clinical Trials. Chest (2018) 153(5):1229-39. doi: 10.1016/j.chest.2017.09.005

17. Fei J, Fu L, Cao W, Hu B, Zhao H, Li JB. Low Vitamin D Status Is Associated With Epithelial-Mesenchymal Transition in Patients With Chronic Obstructive Pulmonary Disease. J Immunol (2019) 203(6):1428-35. doi: 10.4049/jimmunol.1900229

18. Fu L, Fei J, Tan ZX, Chen YH, Hu B, Xiang HX, et al. Low Vitamin D Status Is Associated With Inflammation in Patients With Chronic Obstructive Pulmonary Disease. J Immunol (2021) 206(3):515-23. doi: 10.4049/jimmunol.2000964

19. Damera G, Fogle HW, Lim P, Goncharova EA, Zhao H, Banerjee A, et al. Vitamin D Inhibits Growth of Human Airway Smooth Muscle Cells Through Growth Factor-Induced Phosphorylation of Retinoblastoma Protein and Checkpoint Kinase 1. Br J Pharmacol (2009) 158(6):1429-41. doi: 10.1111/ j.1476-5381.2009.00428.x

20. Khoo AL, Chai LY, Koenen HJ, Oosting M, Steinmeyer A, Zuegel U, et al. Vitamin D(3) Down-Regulates Proinflammatory Cytokine Response to Mycobacterium Tuberculosis Through Pattern Recognition Receptors While Inducing Protective Cathelicidin Production. Cytokine (2011) 55(2):294-300. doi: $10.1016 /$ j.cyto.2011.04.016

21. Khare D, Godbole NM, Pawar SD, Mohan V, Pandey G, Gupta S, et al. Calcitriol [1, 25[OH]2 D3] Pre- and Post-Treatment Suppresses Inflammatory Response to Influenza A (H1N1) Infection in Human Lung A549 Epithelial Cells. Eur J Nutr (2013) 52(4):1405-15. doi: 10.1007/s00394-012-0449-7

22. Reins RY, Baidouri H, McDermott AM. Vitamin D Activation and Function in Human Corneal Epithelial Cells During TLR-Induced Inflammation. Invest Ophthalmol Vis Sci (2015) 56(13):7715-27. doi: 10.1167/iovs.15-17768

23. Gosens R, Stelmack GL, Dueck G, Mutawe MM, Hinton M, McNeill KD, et al. Caveolae Facilitate Muscarinic Receptor-Mediated Intracellular Ca2+ Mobilization and Contraction in Airway Smooth Muscle. Am J Physiol Lung Cell Mol Physiol (2007) 293(6):L1406-18. doi: 10.1152/ajplung.00312.2007

24. Plesa M, Gaudet M, Mogas A, Olivenstein R, Al Heialy S, Hamid Q. Action of 1,25 $(\mathrm{OH})$ on Human Asthmatic Bronchial Fibroblasts: Implications for Airway Remodeling in Asthma. J Asthma Allergy (2020) 13:249-64. doi: 10.2147/JAA.S261271

25. Mazaleuskaya L, Veltrop R, Ikpeze N, Martin-Garcia J, Navas-Martin S. Protective Role of Toll-Like Receptor 3-Induced Type I Interferon in Murine Coronavirus Infection of Macrophages. Viruses (2012) 4(5):901-23. doi: 10.3390/v4050901

26. Halder SK, Goodwin JS, Al-Hendy A. 1, 25-Dihydroxyvitamin D3 Reduces TGFß3-Induced Fibrosis-Related Gene Expression in Human Uterine Leiomyoma Cells. J Clin Endocrinol Metab (2011) 96(4):E754-62. doi: 10.1210/jc.2010-2131

27. Guillot X, Semerano L, Saidenberg-Kermanac'h N, Falgarone G, Boissier M-C. Vitamin D and Inflammation. Joint Bone Spine (2010) 77(6):552-7. doi: 10.1016/j.jbspin.2010.09.018
28. Wen G, Eder K, Ringseis RJ. 1, 25-Hydroxyvitamin D3 Decreases Endoplasmic Reticulum Stress-Induced Inflammatory Response in Mammary Epithelial Cells. PloS One (2020) 15(2):e0228945. doi: 10.1371/ journal.pone. 0228945

29. Damoiseaux J, Smolders J. The Engagement Between Vitamin D and the Immune System: Is Consolidation by a Marriage to be Expected? EBioMedicine (2018) 31:9-10. doi: 10.1016/j.ebiom.2018.04.013

30. Lin R. Crosstalk Between Vitamin D Metabolism, VDR Signalling, and Innate Immunity. BioMed Res Int (2016) 2016:1-5. doi: 10.1155/2016/1375858

31. Koarai A, Yanagisawa S, Sugiura H, Ichikawa T, Akamatsu K, Hirano T, et al. Cigarette Smoke Augments the Expression and Responses of Toll-Like Receptor 3 in Human Macrophages. Respirology (2012) 17(6):1018-25. doi: 10.1111/j.1440-1843.2012.02198.x

32. Veldurthy V, Wei R, Campbell M, Lupicki K, Dhawan P, Christakos S. 25Hydroxyvitamin $\mathrm{D}_{3}$ 24-Hydroxylase: A Key Regulator of $1,25(\mathrm{OH})_{2} \mathrm{D}_{3}$ Catabolism and Calcium Homeostasis. Vitam Horm (2016) 100:137-50. doi: 10.1016/bs.vh.2015.10.005

33. Månsson Kvarnhammar A, Tengroth L, Adner M, Cardell LO. Innate Immune Receptors in Human Airway Smooth Muscle Cells: Activation by TLR1/2, TLR3, TLR4, TLR7 and NOD1 Agonists. PloS One (2013) 8(7): e68701. doi: 10.1371/journal.pone.0068701

34. Federico S, Pozzetti L, Papa A, Carullo G, Gemma S, Butini S, et al. Modulation of the Innate Immune Response by Targeting Toll-Like Receptors: A Perspective on Their Agonists and Antagonists. J Med Chem (2020) 63(22):13466-513. doi: 10.1021/acs.jmedchem.0c01049

35. Ye J, Maniatis T. Negative Regulation of Interferon- $\beta$ Gene Expression During Acute and Persistent Virus Infections. PloS One (2011) 6(6):e20681. doi: 10.1371/journal.pone.0020681

36. Postma DS, Timens W. Remodeling in Asthma and Chronic Obstructive Pulmonary Disease. Proc Am Thorac Soc (2006) 3(5):434-9. doi: 10.1513/ pats.200601-006AW

37. Chee A, Sin DD. Treatment of Mild Chronic Obstructive Pulmonary Disease. Int J Chron Obstruct Pulmon Dis (2008) 3(4):563-73. doi: 10.2147/copd.s3483

38. Restrepo MI, Sibila O, Anzueto A. Pneumonia in Patients With Chronic Obstructive Pulmonary Disease. Tuberc Respir Dis (Seoul) (2018) 81(3):18797. doi: $10.4046 / \operatorname{trd} .2018 .0030$

39. Wu C, Chen X, Cai Y, Xia J, Zhou X, Xu S, et al. Risk Factors Associated With Acute Respiratory Distress Syndrome and Death in Patients With Coronavirus Disease 2019 Pneumonia in Wuhan, China. JAMA Intern Med (2020) 180(7):934-43. doi: 10.1001/jamainternmed.2020.0994

40. Skevaki C, Karsonova A, Karaulov A, Xie M, Renz H. Asthma-Associated Risk for COVID-19 Development. J Allergy Clin Immunol (2020) 146(6):1295-301. doi: 10.1016/j.jaci.2020.09.017

41. Matsumoto K, Saito H. Does Asthma Affect Morbidity or Severity of COVID19? J Allergy Clin Immunol (2020) 146(1):55-7. doi: 10.1016/j.jaci.2020.05.017

Conflict of Interest: The authors declare that the research was conducted in the absence of any commercial or financial relationships that could be construed as a potential conflict of interest.

Publisher's Note: All claims expressed in this article are solely those of the authors and do not necessarily represent those of their affiliated organizations, or those of the publisher, the editors and the reviewers. Any product that may be evaluated in this article, or claim that may be made by its manufacturer, is not guaranteed or endorsed by the publisher.

Copyright $\odot 2021$ Plesa, Gaudet, Mogas, Jalaleddine, Halayko, Al Heialy and Hamid. This is an open-access article distributed under the terms of the Creative Commons Attribution License (CC BY). The use, distribution or reproduction in other forums is permitted, provided the original author(s) and the copyright owner(s) are credited and that the original publication in this journal is cited, in accordance with accepted academic practice. No use, distribution or reproduction is permitted which does not comply with these terms. 